\title{
TURISMO, PAISAJE Y TERRAZAS DE CULTIVO
}

Joaquín SABATÉ BEL

Este artículo pretende centrar su reflexión en la relación entre paisaje, ordenación del territorio y producto turístico. Para hacerlo discutiremos de entrada tres premisas teóricas comúnmente aceptadas e intentaremos ejemplificar dicha discusión con la explicación de un caso de estudio concreto, el Plan Insular de Ordenación del Territorio de Tenerife, PIOT en adelante.

Turismo, paisaje, retribución del paisaje, agricultura, planeamiento territorial

\section{TOURISM, LANDSCAPE AND AGRICULTURAL TERRACES}

The present article focuses on the relationship between landscape, land use management and tourism. It begins by discussing three widely-accepted theoretical premises and frames the discussion in the context of a specific case study: the island of Tenerife's land use management plan (PIOT).

Tourism, landscape, landscape costs, agriculture, territorial planning 
Hace unos días releía, una vez más, un pequeño cartel que decía, más o menos así:

"Grandiosa excursión a los tres archipiélagos: Azores-Madeira-Canarias.

Con el magnifico crucero The Traveller, de 2.500 Toneladas y 3.000 caballos.

Salida de Londres el 10 de mayo a las 7 de la tarde y regreso el 14 de junio al mediodia.

Guias y carruajes para todas las excursiones. Estancia en tierra en hoteles de primera categoria. Los señores pasajeros no tendrán que hacer ningún gasto a parte del precio estipulado.

Precio del viaje comprendidos todos los gastos 78 libras esterlinas

Para toda clase de informaciones dirigirse a las oficinas de la Agencia Baker and Company.

Se desea un cicerone-intérprete."

De este modo iniciaba Julio Verne una breve, magnífica, escasamente conocida y absolutamente recomendable novela hace 140 ańos: Agencia Thompson \& Cia.

Porque es la agencia Thompson, competidora de la Baker, y el vapor Seamew, quienes a la postre, y a un precio algo inferior, realizar el anunciado crucero. Un crucero que, tras costear Lanzarote recala en Santa Cruz de Tenerife para, siguiendo los pasos de sus admirados Alexander von Humboldt y Sabino Berthelott, mostrarnos La Orotava, La Laguna, El Puerto de la Cruz o el Teide. Pero lo más interesante es que aquellos viajeros que atracan en el muelle de Santa Cruz, encuentran allí numerosos buques provenientes de Le Havre, Marsella, Hamburgo o Génova.

Julio Verne, que anticipa tantas cosas, y en este caso los operadores turísticos, no se inventa en cambio la estampa de un muelle de Santa Cruz lleno de veleros y vapores. Son absolutamente reales, hacen escala regularmente en Tenerife y posibilitan el arranque de la industria del turismo en la isla. Se trata por tanto de una industria más que centenaria, que tiene por ello la misma legitimidad, el mismo pedigrí, que las bergadanas o los altos hornos. 

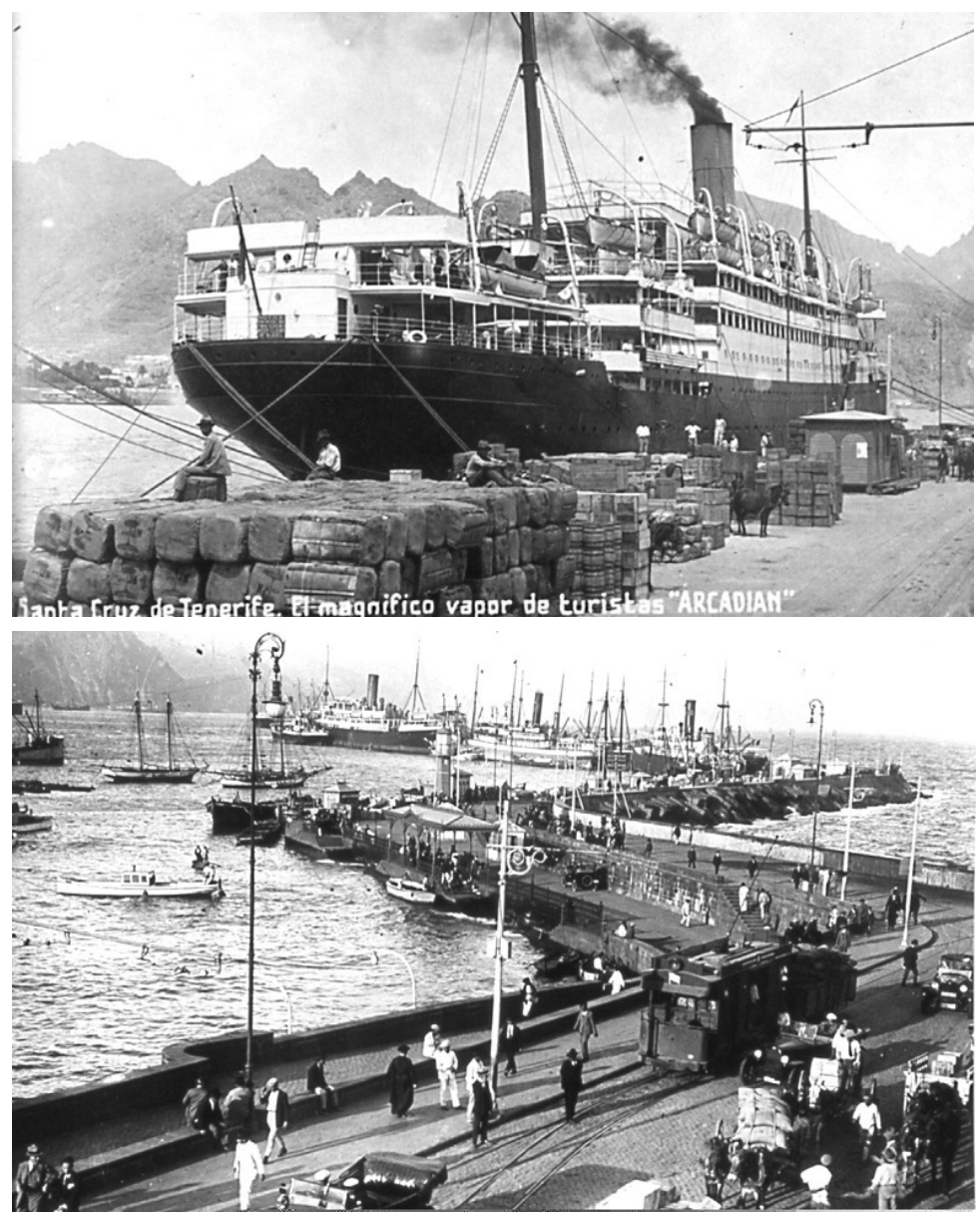

Cuando hace más de 20 años el Cabildo de Tenerife encarga la redacción del Plan Insular de Ordenación del Territorio (en adelante PIOT), aquella industria centenaria parece estar sumida en una crisis grave, una de las diversas crisis cíclicas que le han afectado. ${ }^{1}$

¿Pero se trata de una crisis de crecimiento? ¿De una crisis de modelo? ¿De un desajuste entre oferta y demanda? ¿De una excesiva oferta en una isla que depende para su subsistencia del turismo?

1 La isla de Tenerife constituye uno de los más relevantes laboratorios donde medir dicha relación. Con una tradición más que centenaria en el desarrollo del turismo atrae hoy más de cinco millones de visitantes anuales. El PIOT se propone a su vez a finales de los años ochenta, como una de las primeras experiencias de ordenación territorial comprensivas, donde se han de enfrentar las diferentes escalas y dimensiones de las actividades que se desarrollan sobre un territorio con las características de éste, y también, genéricamente, con su paisaje. 


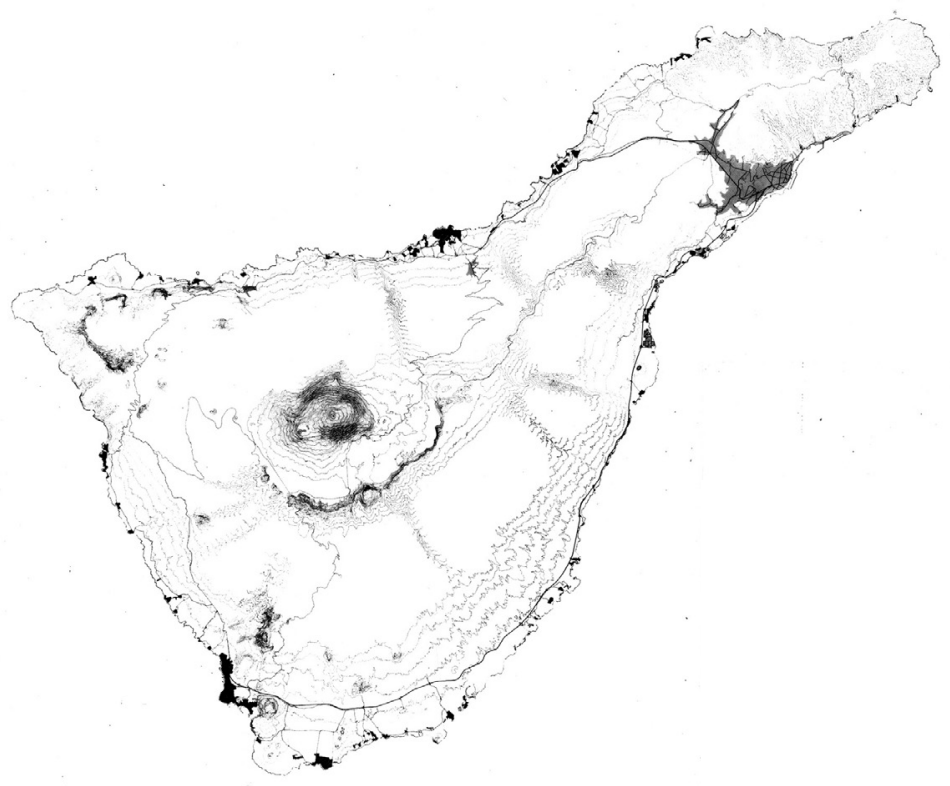

Tras un detenido análisis se llega a una doble conclusión.

La convicción de no estar en crisis, sino en una mutación. No se trata de utilizar simplemente un sinónimo, sino del hecho que las mutaciones puedan gestionarse y las crisis no tanto. Pero, ¿qué tipo de mutación?

La respuesta es: una mutación hacia un nuevo modelo de turismo, de proyecto turístico. Hoy lo llamaríamos turismo sostenible, pero entonces la palabra no era de uso tan común y generalizado y se define como un turismo soportable ambientalmente (a corto y largo plazo); viable económicamente y aceptable socialmente. $\mathrm{O}$ se puede expresar asimismo diciendo que ha que ser un turismo que ponga el paisaje (natural y construido) como centro de sus preocupaciones y objeto principal de la ordenación.

El turismo se ordena por tanto en el PIOT sobre la base de la unidad de paisaje, buscando su integración en un entorno antropizado. Porque el paisaje en Tenerife se nos muestra con una clara impronta humana. Un gran urbanista comparó Tenerife con una "gran maceta", al objeto de enfatizar las escasas condiciones iniciales del territorio para ser ocupado y cultivado.

Por su condición abrupta y facturada, por su origen volcánico y sus considerables pendientes, eran escasos los ámbitos con terrenos sedimentarios, donde los cultivos fuesen posibles directamente sobre suelo fértil. 
Así el terreno antropizado fue siempre, en gran medida una "gran maceta", pues en contadas ocasiones pudo ser directamente utilizado como soporte para la agricultura.

Pero el habitante de Tenerife supo convertir dicha desventaja inicial en una hermosa obra colectiva de manipulación, de construcción del paisaje.

Los bancales clásicos en todo suelo en pendiente, se complementan en este caso con la necesaria creación de un manto vegetal para el cultivo, con costosas obras de protección contra el viento, con el trazado de caminos en terrenos abruptos y con el relleno con tierras de prestación, con la construcción de lechos de drenaje y de muros de contención del nuevo suelo vegetal, o con sistemas muy peculiares y sofisticados de captación y transporte de agua.

Con todo ello se produce la transformación de eriales y terrenos de condiciones iniciales tremendamente desventajosas, en extensas y magníficas áreas productivas.

La agricultura es, hasta bien recientemente, la "constructora" del territorio insular, del que resulta una forma altamente artificial. Ha sido la constructora histórica de nuestro paisaje.

Pero bien recientemente el turismo toma el relevo en este cometido constructor. Y el turismo esta hoy estrechamente vinculado al paisaje en el que se inserta.

Hoy ya no resulta imprescindible insistir en dicha estrecha interdependencia entre Turismo y Paisaje, aunque si lo fue hace 20 años. La Organización Mundial de Turismo, la Secretaría de Estado para el Medio Ambiente, el Parlamento Europeo, o los participantes en cualesquiera congresos de Turismo insisten en dicha estrecha interdependencia, entre turismo y paisaje.

Pero el Plan Insular quiso ir algo más allá. Quiso rebatir aquella interpretación fatalista del turismo como depredador del medio en que se inserta, negar que los desarrollos turísticos deban necesariamente afectar el paisaje circundante.

Y para ello resulta imprescindible distinguir lo turístico de lo inmobiliario y defender que el turismo, en tanto que motor de la economía tinerfeńa, en tanto que sector predominante y capaz de producir importantes excedentes, es la principal oportunidad para poner en valor el paisaje, y debe aceptar la responsabilidad de retribuirlo y recuperarlo.

Quisiera destacar algunos aspectos relevantes de la ordenación territorial del turismo contenida en el Plan Insular. Uno de los principios de nuestro abordaje es que la principal razón de ser el turismo es la producción de paisaje y que el paisaje, en su más amplia acepción es el principal recurso del turismo, y no el sol y la playa. Pero antes conviene rebatir tres premisas. 

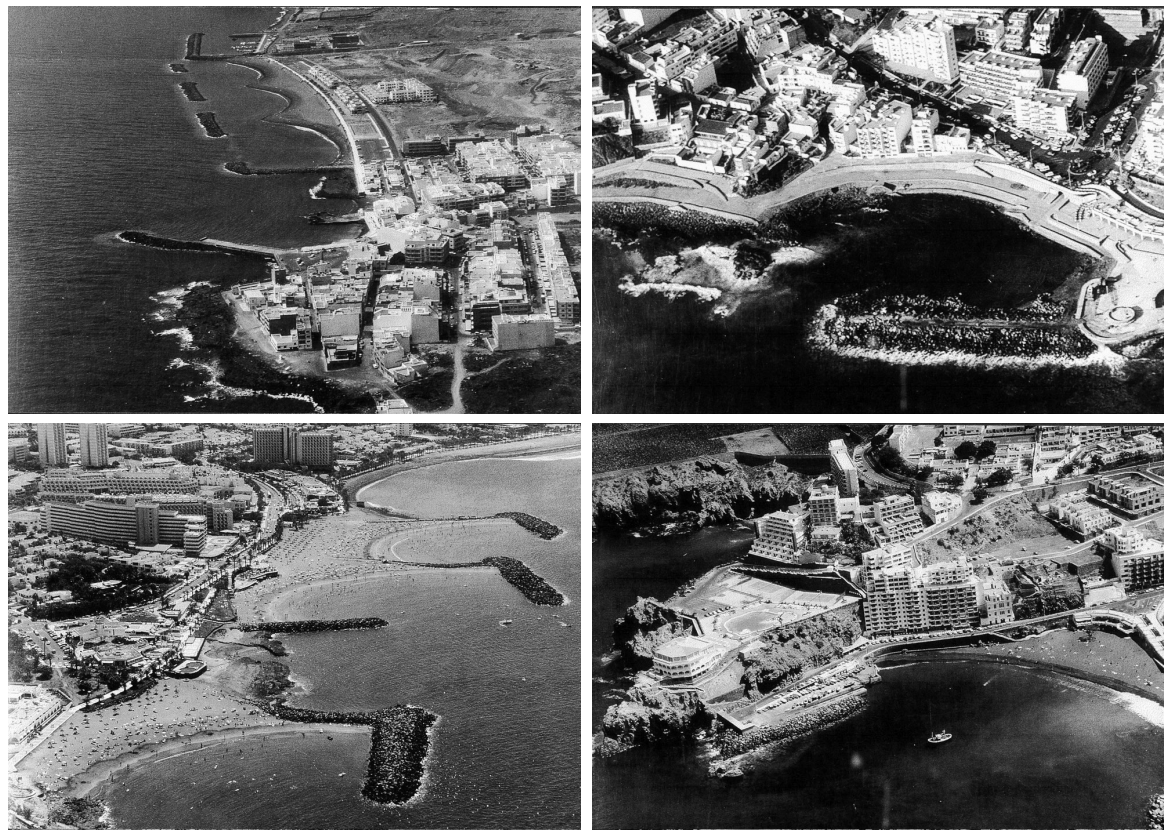

Primera premisa: El turismo actúa como depredador del territorio, compite con ventaja por la ocupación de espacios de especial interés natural o agrícola.

En la presentación de unas Jornadas sobre Turismo y Medio Ambiente en Canarias se ponía claramente de manifiesto que “... desde hace algunos años los operadores turísticos de nuestras islas realizan esfuerzos por diversificar su oferta, con lo que, aunque sigue predominando el turismo de sol y playa, se está produciendo una creciente presión de la actividad turística sobre áreas cada vez más amplias del territorio insular. Este fenómeno, junto con la mayor demanda de los habitantes de nuestras principales ciudades, hace que sea cada vez más difícil la preservación de nuestro medio ambiente en general y en particular de nuestros ecosistemas más frágiles...”.

Esta interpretación podríamos seguramente generalizarla a muchos otros contextos de todo el mundo. Determinadas actividades que son capaces de generar más plusvalías a propietarios, promotores o empresarios, desplazan a otras tradicionales en una competencia desigual. Cabe destacar diferentes manifestaciones de este problema. Por un lado tenemos la presión directa para reclasificar en los planes urbanísticos el suelo ocupado por áreas agrícolas y espacios de interés natural. Todo ello está vinculado a expectativas de futura retribución del suelo, las más de las veces sin capacidad o voluntad inmediata de transformación. 
Y si el problema de la competencia por uso del suelo en las zonas costeras adquiere hoy por hoy mayor relevancia en las comarcas de mayor desarrollo turístico, aquellos municipios en que la implantación de dicha actividad turística es escasa, ven asimismo en la clasificación urbanística la posibilidad de mejorar la economía municipal.

Cabría contraponer a este tipo de dinámicas una alternativa teórica. Quizás una mayor participación de la totalidad del territorio en la actividad turística no debiera plantearse como alternativa a la agricultura, ni significar necesariamente la instalación de grandes complejos turísticos en los suelos de mayor capacidad agraria. Se trataría de jugar la baza de una diversidad, que, sin negar el crecimiento de los núcleos urbanos y el desarrollo turístico, configure una oferta diferente, que conserve las características del paisaje, a las que la agricultura, u otras actividades, aportan una contribución tan relevante. Igualmente podrían ensayarse mecanismos para que los beneficios derivados del turismo repercutieran en la conservación de la agricultura y del paisaje agrícola del que el turismo se beneficia.

Segunda premisa: El turismo no es una industria.

Hace ya tiempo que el turismo viene siendo lo que es hoy en día: un viaje barato, organizado, mediado por empresas (agencias, transportistas), grupal, medido y programado de antemano. Julio Verne describe hace ya siglo y medio, el nacimiento y desarrollo de los primitivos viajes de turismo, aquellos

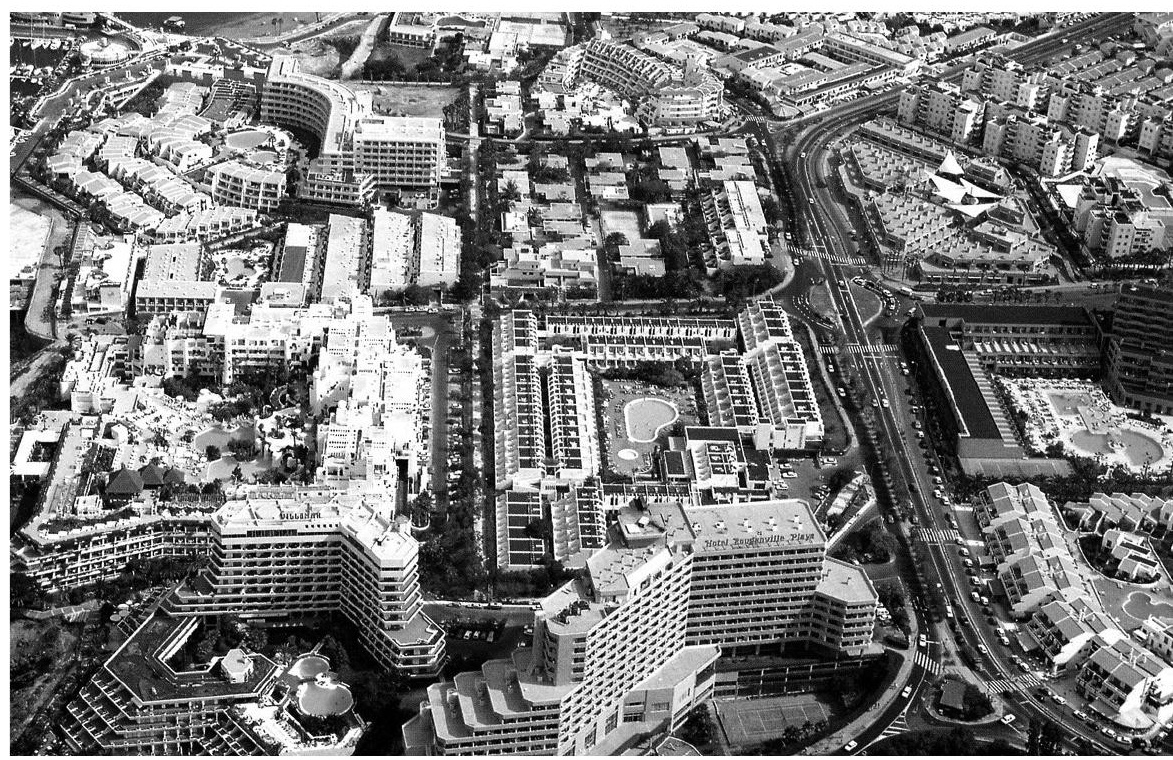


social, una repercusión diferida que deberá abonar en su conjunto la propia sociedad. Pero resulta difícil encontrar una industria que asuma íntegramente todas sus externalidades negativas, pues a la larga eso provoca su desaparición.

Sin embargo en la industria turística se producen aparentemente deseconomías externas en la elaboración del producto turístico (congestión de los ámbitos turísticos, destrucción o degradación del paisaje, calidad de las aguas...), que afectan la calidad de lo que se ofrece y a su vez a los residentes del área.

Esta supuesta paradoja es el resultado de la multiplicidad de intereses que se producen sobre el territorio, intereses fundamentales y contrapuestos, de las empresas turísticas, de servicios o constructoras, de los consumidores...

La degradación de un territorio turístico guarda una relación directa con esta contraposición entre intereses turísticos e inmobiliarios. No es la industria turística la que destruye el paisaje, su principal activo, sino la inmobiliaria. Ello afecta la rentabilidad de las empresas turísticas, a la propia valoración de la oferta (menor calidad y por tanto retribución en un entorno degradado, disminución de la afluencia, o de la estancia media,...). En dichas circunstancias resulta recomendable, o incluso imprescindible, la adopción de medidas correctoras de diverso tipo, y entre éstas, aquellas que aseguren un uso correcto del recurso paisaje, su mantenimiento y en su caso mejora, incidiendo, si es posible, en la conducta de los agentes, al objeto de que tengan en cuenta el coste de producción y conservación de este recurso.
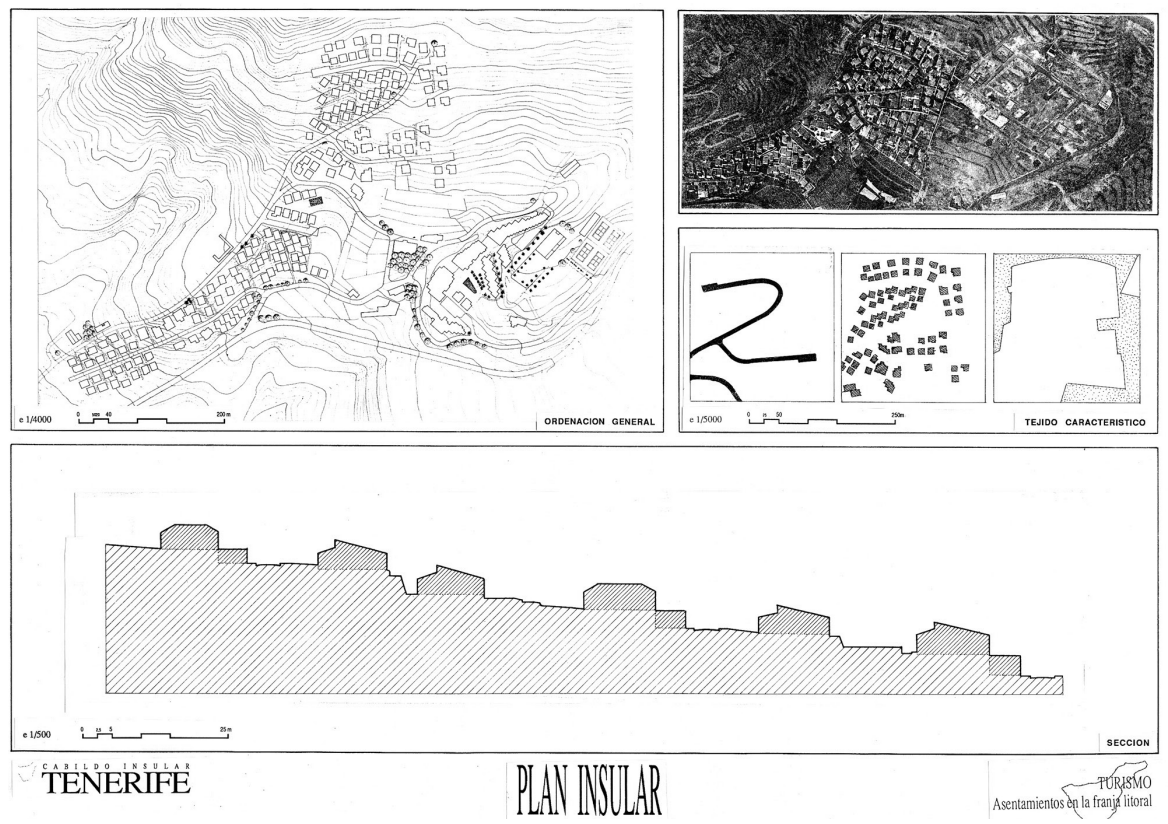
Una vez planteadas estas tres premisas vamos a detenernos en los tres objetivos vinculados a cada una de ellas que define el PIOT, y que se convierten en las bases de la ordenación del turismo en dicho plan.

El primero de los objetivos plantea que conviene disociar el desarrollo turístico de lo que tiene de proceso inmobiliario, del crecimiento urbanístico tradicional. Esto implica admitir proyectos turísticos lo en los distintos tipos de suelo: urbano, rústico y urbanizable, con tratamientos y parámetros diferentes en cada uno de ellos y con los correspondientes dimensionado y restricciones.

Este objetivo lleva asociados otros, tales como:

a) incidir en la modificación del modelo vigente, basado solo en el crecimiento por extensión de las áreas existentes, o en la aparición de nuevos enclaves,

b) reducir la tensión originada por las clasificaciones urbanísticas, asociando los desarrollos a los distintos regímenes de suelo y vinculando unas áreas con otras,

c) reducir los inconvenientes de asociar lo turístico y lo inmobiliario, los lastres del vínculo entre establecimiento turístico y propiedad del suelo.

A partir del análisis de diversos modelos turísticos y de la discusión de las alternativas y parámetros más adecuados, de los ámbitos de desarrollo posibles, de las restricciones y regulaciones aplicables, cabe plantear la optimización de los recursos vinculados al desarrollo turístico, tanto públicos, como privados.

En el suelo urbano el PIOT propuso orientar la intervención en áreas turísticas ya desarrolladas. Ello implica sustituir la inversión en nuevas extensiones por la recuperación de tejidos y rehabilitación, o incluso substitución, de piezas obsoletas. Para ello elabora un análisis detallado y una clasificación en categorías de todos asentamientos vinculados al turismo. A partir de ello se plantean propuestas de reestructuración, remodelación; reequipamiento, reurbanización, completamiento a través de Planes Especiales; se establecen medidas de mejoras sobre la infraestructura, el paisaje, los servicios... Años después esta política se aplica ampliamente en otros destinos como Mallorca, igualmente con amplia tradición turística.

Posibilitar la actividad turística en suelo rústico (turismo rural) supone no tan solo con la voluntad de encauzar una demanda emergente, o de adelantarse a un tratamiento inadecuado de la misma si se deja exclusivamente en manos de los operadores turísticos, sino partir del convencimiento de que constituye a su vez una manera fórmula de enriquecer la oferta global, de recuperar elementos patrimoniales y de impulsar el desarrollo del medio rural. Al objeto de encajar estos objetivos el PIOT procede a la identificación de senderos, elementos y núcleos de especial interés patrimonial, restringiendo 
el turismo rural tan solo a la rehabilitación de lo edificado en un conjunto de caseríos existentes catalogados por su interés patrimonial. Para llevar a cabo las intervenciones sería preciso la aprobación de un Plan Especial de Protección del Patrimonio Rural, admitiéndose iniciativas impulsadas por particulares e incentivadas por la Administración.

Los planes urbanísticos suelen seleccionar, en función de sus características, determinados terrenos como susceptibles de acoger desarrollos turísticos. En España lo hacen clasificándolos como suelo urbanizable. Ello da lugar a lo que se ha denominado "la lotería del planeamiento" y a una continua presión por parte de los propietarios no incluidos, al objeto de serlo en una próxima ocasión. Al objeto de evitar agravios comparativos en la selección de unos u otros ámbitos, el PIOT propuso en cambio incluir una amplísima extensión de terrenos con características adecuadas para ser razonablemente susceptibles de acoger desarrollos turísticos, como suelo urbanizable no programado. 2 Esto, que puede parecer un enorme contrasentido, al comprometer una considerable parte del territorio, venía contrarrestado con diversas medidas. La primera era la bajísima edificabilidad propuesta aprobada, lo que exige para cada operación mucho más terreno y en definitiva el acuerdo entre propietarios. La segunda implica la salvaguarda de todos aquellos terrenos con valores patrimoniales, naturales o culturales, que generan aprovechamiento edificatorio, pero sin que éste se pudiera materializar encima suyo, debiendo trasladarse a otra parcela "sin atributos tan valiosos". Con ello se consigue ubicar igualmente los proyectos turísticos en determinados lugares, aquellos más adecuados, pero a la vez obtener la cesión a los Ayuntamientos de aquellos otros suelos valiosos, cuyos propietarios se resarcen materializando sus derechos en los "ámbitos edificables" vecinos. Con la cesión se superan futuras tensiones de reclasificación de terrenos que pasan a incorporarse al patrimonio público y se rodean los productos turísticos de espacios naturales (barrancos, bosques, laderas, malpaíses, costa) o culturales (agrícolas), que los cualifican.

El segundo objetivo supone introducir mecanismos de concertación respecto al ritmo de entrada en el mercado de nuevas camas y de composición más adecuada de la oferta, primando aquellas intervenciones que dotan de valor añadido a los desarrollos turísticos por los servicios asociados a los mismos, por las mejoras introducidas en el paisaje, o porque suponen una ampliación selectiva y justificada de un nuevo segmento de demanda.

Se parte de la constatación de que la oferta actual ha alcanzado un volumen más que suficiente para atender una demanda que haga operativo el sistema. Todo incremento debe exigir una recalificación de lo existente, 
El PIOT defiende, en función de éstas y otras consideraciones, una opción intermedia. Se trataría de pactar un crecimiento ajustado de la oferta, proponiendo para ello diversos mecanismos especialmente atentos a la forma del territorio. Dicha concertación debe extenderse al conjunto del sector, administración pública y restantes agentes implicados (empresarios turísticos y usuarios...) y tener como objetivos básicos diversificar la futura oferta y recalificar la existente. Se plantea de hecho consensuar un ritmo de ajuste en función de una tasa de ocupación que genere excedente y un nivel suficientemente competitivo de las empresas, que redunde en su capacidad de adecuación y modernización y en la mejora de la calidad del producto turístico, adecuando la oferta al dispositivo territorial, a los recursos y necesidades.

Uno de los retos básicos en cuanto a la ordenación territorial del turismo consiste en acertar a trasladar, con las debidas precauciones, toda la sabiduría de la industria convencional al turismo. Partiendo del turismo como una industria y de las anteriores premisas, los estudios del PIOT llegan a las siguientes conclusiones:

1. La estructura socioeconómica de Tenerife no muestra posibilidades, a corto o medio plazo, de eliminar su dependencia del turismo masivo, tanto por el nivel de construcción y empresas desarrolladas con esta finalidad, como por su peso en ingreso, renta y empleo, o por la propia imagen internacional consolidada.

2. Eso lleva a reconocer el protagonismo del turismo masivo, a defender la mejora de sus estructuras y equipamientos, su recalificación, corrigiendo la dinámica que le abocaría a ser disfuncional y desagradablemente masivo. Lleva por tanto a aceptar el carácter de turismo de masas, a proponer las mencionadas medidas y a profundizar en las posibilidades que ofrece una mayor diversificación, una potenciación de una emergente oferta diversificada

3. O nos lleva a preguntarse ¿Qué sentido tiene discutir el número de plazas en términos absolutos?

La discusión de dichos límites en términos de capacidad de carga (del territorio, de la infraestructura, de los recursos...) constituye una evaluación sumamente compleja, donde hay que tener especialmente en cuenta que no se puede regular con carácter estable y externamente a ella, una actividad que produce mercancías, y que se mueve de acuerdo a las coyunturas del mercado. La determinación de un número límite de plazas puede llegar a ser muy útil desde la ordenación territorial, pero dicho umbral de condiciones (más que límite fijo y rígido) debe atender a varios criterios, como, por ejemplo, una dimensión ajustada de cada modelo de desarrollo, adecuada al mercado internacional y atenta a las características específicas de cada unidad de paisaje de Tenerife. 
El tercer objetivo plantea el paisaje como centro de las preocupaciones y hacerlo objeto principal de la ordenación; ordenar el turismo sobre la base de la unidad de paisaje.

Nos referimos al paisaje, al igual que cuando hablamos del territorio, en su acepción más general, que comprende el paisaje y los recursos naturales, pero asimismo el paisaje urbano $\mathrm{y}$, en concreto, el propio paisaje de los núcleos turísticos, pero también, especialmente, el paisaje agrícola construido durante siglos.

El paisaje constituye la materia prima y el producto esencial del turismo. El recurso natural exigido no es tan solo la playa, o un buen clima. Se requieren otros componentes territoriales hasta ahora escasamente atendidos, entre ellos el paisaje construido, y en buena medida el que ha construido la

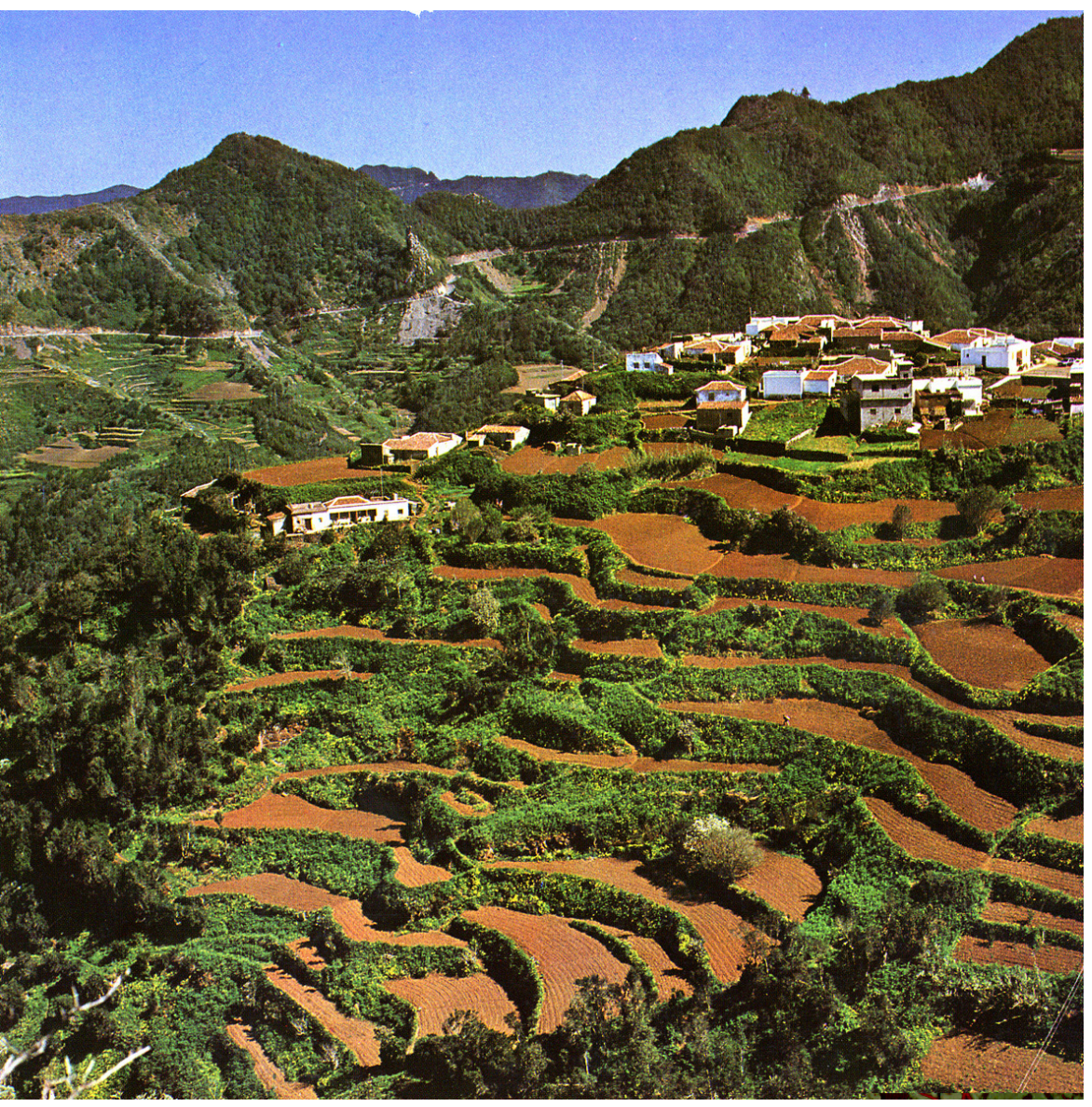




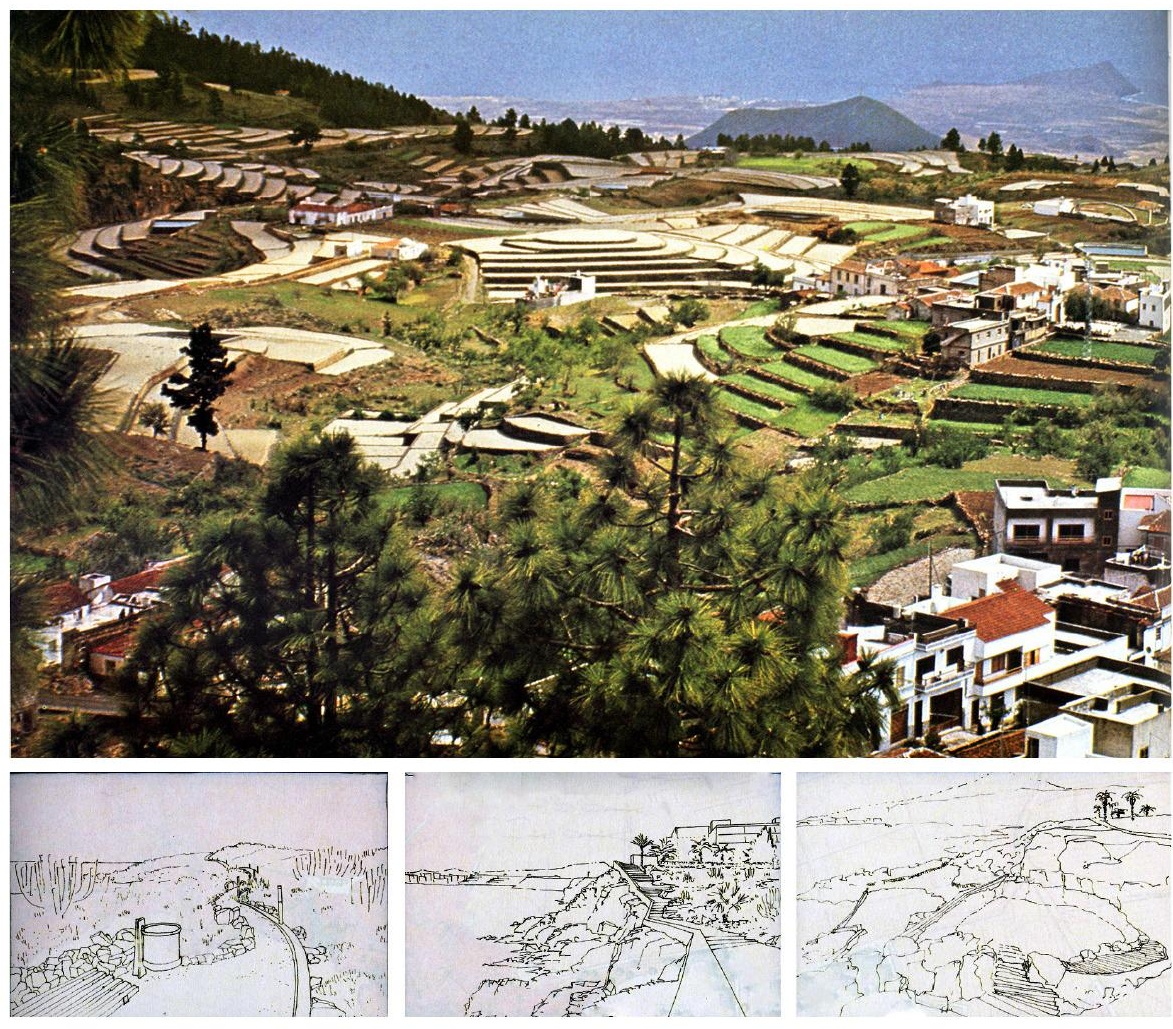

agricultura tradicional. Por ello la ordenación del turismo ha de hacerse sobre la base de dicha interdependencia. Es imprescindible que las intervenciones turísticas se planteen no tan solo con un exquisito cuidado por el medio, sino que supongan de hecho operaciones de reinversión en paisaje, al objeto de garantizar una proyección adecuada de una identidad turística bien singular.

El PIOT propone la ordenación del turismo a través de las Unidades de Paisaje: ámbitos territoriales con relativa homogeneidad en cuanto a los modelos de desarrollo turístico. En cada una de las Unidades se establecen los criterios, mecanismos y operaciones de reinversión en el paisaje y las medidas para su mantenimiento y mejora (vehicular estudios sobre demanda; crear ofertas diferenciadas dentro del producto "Tenerife"; vincularlas a recursos potenciales; establecer un marco de valoración medioambiental, de compensación, de mantenimiento, de recuperación del paisaje, de evaluación de las necesidades de reinversión...). Para ello se incluye:

a) Una evaluación de recursos y necesidades de cada Unidad de Paisaje, de sus potencialidades, déficit y carencias. 
b) El establecimiento de condiciones de carácter general de mantenimiento y mejora del paisaje, de corrección de desajustes, de reposición.

c) La definición en cada Unidad de Paisaje de un conjunto de acciones necesarias, tales como, mejoras del sistema viario, dotaciones, ordenación o equipamiento del litoral, adecuación de edificios e instalaciones.

Se proponen además diferentes niveles de transferencias de los recursos generados por los proyectos turísticos, al objeto de ser reinvertidos en la mejora del producto global. Un primer nivel de transferencias implicaría la aprobación de un Plan-Programa que recoja las anteriores propuestas y las establezca como condición básica en la redacción de los Programas de Actuación Urbanística.

La legislación española exige ue los promotores de planes urbanísticos deben ceder a los Ayuntamientos el 15\% del aprovechamiento edificatorio de los mismos, que pasa a integrar parte de su patrimonio de suelo. Por lo general los Ayuntamientos que reciben dichos suelos en áreas turísticas no saben que hacer con ellos y acaban malversándolos. Frente a ello se sugiere que un segundo nivel de transferencias pasaría por traducir dicho potencial de recursos en una proporción de suelo de valor equivalente en los núcleos cercanos de residencia estable. Esto permitiría completar sus dotaciones o abordar la construcción de vivienda pública con destino a los trabajadores de las mismas áreas turísticas. Igualmente se proponía que los ingresos derivados directa o indirectamente de la actividad turística (IBI, tasas, licencias, impuestos específicos...) fueran destinados a inversiones de mejora de las dotaciones y recursos de cada Unidad de Paisaje.

Un tercer nivel de transferencias implicaría computar, como se decía antes, a efectos del número de plazas admisible en el desarrollo del suelo urbanizable no programado con destino turístico, las áreas de interés agrícola o natural incluidas en dichos sectores o en el conjunto de la Unidad de Paisaje, proponiendo su mantenimiento como espacios cultivados o en estado natural, vinculados a la explotación turística.

Estas transferencias suponen para el desarrollo turístico seguir disponiendo de un paisaje de notable interés en su entorno, sin necesidad de adquirir la propiedad de dichos suelos, eliminando la tensión de una futura transformación de dichas áreas agrícolas. Para la explotación agrícola supone una transferencia de recursos y la eliminación de las expectativas de transformación. Para el conjunto del territorio supone la garantía de un desarrollo más equilibrado, más ajustado al valor natural o a la inversión histórica (paisaje agrícola) de cada uno de sus fragmentos. 
El sector turístico es el principal interesado en retribuir y recuperar el paisaje y la principal oportunidad para ponerlo en valor. Para ello se plantea establecer mecanismos para que los beneficios derivados del turismo repercutan en la conservación de la agricultura y del paisaje agrícola del que aquel se beneficia.

El conjunto de propuestas del PIOT buscan asegurar un paisaje de notable valor en el entorno de los desarrollos turísticos sin necesidad de adquirir la propiedad del suelo, eliminando la tensión de cualquier futura transformación.

Para las explotaciones agrarias supone la eliminación de las expectativas futuras de urbanización, de recalificación urbanística, pero al tiempo la eliminación de un agravio comparativo y la transferencia de recursos.

Para el conjunto del territorio implica la garantía de un desarrollo más equilibrado, más atento a sus valores (naturales) y a la inversión histórica (agrícola).

Con ello se pretende reforzar la complementariedad del paisaje, del medio natural y cultural con el turismo, con áreas de cultivo vinculadas a desarrollos turísticos, caseríos de interés patrimonial que puedan tener una economía complementaria en el turismo rural; inversiones para la reconstrucción, mejora o mantenimiento de elementos básicos del paisaje agrícola o natural; transferencia de recursos generados por la actividad turística; o esencialmente, diseño de pautas generales para la más adecuada inserción de los desarrollos turísticos en un paisaje natural o primorosamente construido por el hombre, respetándolo y valorizándolo.

Volviendo pues al inicio, cuando Julio Verne nos invita a pasear con la Agencia Thompson por las islas, cuando nos lleva a visitar el Valle de la Orotava (siguiendo el trayecto y las descripciones de Alexander von Humboldt y Sabino Berthelott nos está de hecho hablando de turismo y paisaje. Como en tantas otras cosas más de cien ańos después, Julio Verne sigue siendo profético. Más Julio Verne y menos operadores turísticos multinacionales. O dicho de otro modo: en última instancia, todas las medidas del plan Insular relativas al turismo persiguen esencialmente el reconocimiento expreso de esta complementariedad y devolver al paisaje y a la actividad agrícola, parte de los beneficios que suponen para el turismo.

O como reza el título, vincular turismo, paisaje y terrazas de cultivo. 
Joaquín Sabaté Bel, Dr. Arquitecto

Catedrático de Urbanismo Coordinador del Programa de Máster y Doctorado en Urbanismo Departamento de Urbanismo y Ordenación del Territorio (DUOT) Universidad Politécnica de Cataluña (UPC) joaquin.sabate@upc.edu 